\title{
Crystal structure of 6-(4-fluorophenyl)-4-methoxy- $2 \mathrm{H}$-pyran-2-one, $\mathrm{C}_{12} \mathrm{H}_{9} \mathrm{FO}_{3}$
}

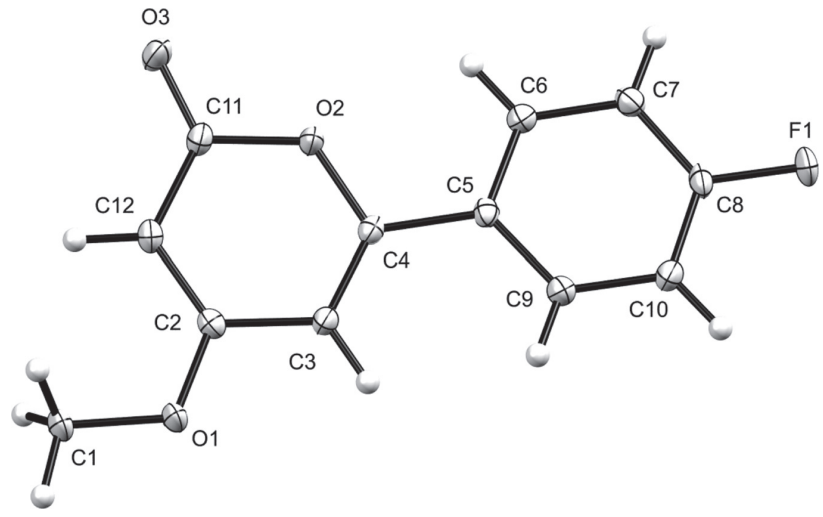

https://doi.org/10.1515/ncrs-2019-0752

Received October 10, 2019; accepted November 8, 2019; available online December 5, 2019

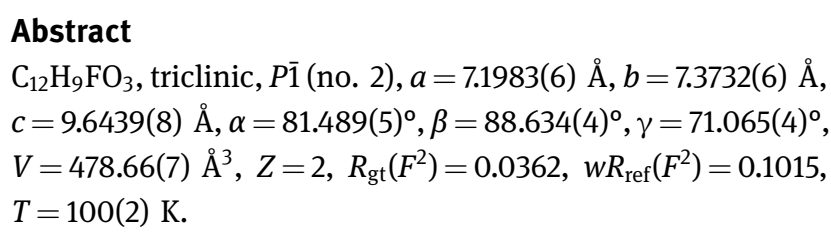

CCDC no.: 1964527

The molecular structure is shown in the figure. Table 1 contains crystallographic data and Table 2 contains the list of the atoms including atomic coordinates and displacement parameters.

\section{Source of material}

The dianion of ethyl acetoacetate $(1.83 \mathrm{~g}, 14.04 \mathrm{mmol})$ was formed by the sequential treatment of the parent compound in THF $(60 \mathrm{~mL})$ with $\mathrm{NaH}(60 \%$ dispersion in mineral oil, $1.12 \mathrm{~g}, 28.0 \mathrm{mmol}$ ) and $n$-butyllithium $(2.5 \mathrm{M}$ in hexane, $9.2 \mathrm{~mL}, 23.20 \mathrm{mmol}$ ). Addition of ethyl 4-fluorobenzoate ( $2.36 \mathrm{~g}, 14.04 \mathrm{mmol}$ ) to the reaction mixture yielded ethyl $(Z)$ 5-(4-fluorophenyl)-5-hydroxy-3-oxopent-4-enoate. Refluxing

*Corresponding author: Sizwe J. Zamisa, University of KwaZulu-Natal, Private Bag X54001, Westville Campus, Westville 4000, Durban, South Africa, e-mail: Zamisas@ukzn.ac.za. https://orcid.org/0000-0003-1968-381X

Grace Obi and Fanie R. van Heerden: University of KwaZulu-Natal, School of Chemistry and Physics, Private Bag X01, Pietermaritzburg Campus, Pietermaritzburg 3209, Durban, South Africa

○ Open Access. ( 2019 Grace Obi et al., published by De Gruyter. (c) BY License.
Table 1: Data collection and handling.

\begin{tabular}{ll}
\hline Crystal: & Colourless Rod \\
Size: & $0.50 \times 0.19 \times 0.16 \mathrm{~mm}$ \\
Wavelength: & Mo $K \alpha$ radiation $(0.71073 \AA$ A $)$ \\
$\mu:$ & $0.12 \mathrm{~mm}^{-1}$ \\
Diffractometer, scan mode: & Bruker APEX-II, $\varphi$ and $\omega$ \\
$\theta_{\text {max }}$, completeness: & $27.4^{\circ}, 98 \%$ \\
$N(h k l)_{\text {measured }}, N(h k l)_{\text {unique }}, R_{\text {int }}:$ & $8040,2142,0.018$ \\
Criterion for $I_{\text {obs }}, N(h k l)_{\text {gt }}:$ & $I_{\text {obs }}>2 \sigma\left(I_{\text {obs }}\right), 1942$ \\
$N(\text { param })_{\text {refined }}:$ & 146 \\
Programs: & Bruker [1], SHELX [2, 3], \\
& Mercury [4]
\end{tabular}

Table 2: Fractional atomic coordinates and isotropic or equivalent isotropic displacement parameters $\left(\AA^{2}\right)$.

\begin{tabular}{lrrrr}
\hline Atom & $\boldsymbol{x}$ & $\boldsymbol{y}$ & $\boldsymbol{z}$ & $\boldsymbol{U}_{\text {iso }}{ }^{*} \boldsymbol{U}_{\text {eq }}$ \\
\hline F1 & $0.34170(12)$ & $0.79159(12)$ & $0.91465(8)$ & $0.0224(2)$ \\
O1 & $0.31232(14)$ & $0.06558(13)$ & $0.28267(9)$ & $0.0165(2)$ \\
O2 & $0.12032(13)$ & $0.63559(12)$ & $0.33314(9)$ & $0.0147(2)$ \\
O3 & $-0.02087(15)$ & $0.73199(13)$ & $0.12224(10)$ & $0.0207(2)$ \\
C1 & $0.2746(2)$ & $0.00563(18)$ & $0.15319(13)$ & $0.0180(3)$ \\
H1A & 0.132569 & 0.047985 & 0.134322 & $0.027^{*}$ \\
H1B & 0.328030 & -0.135939 & 0.161302 & $0.027^{*}$ \\
H1C & 0.337513 & 0.064182 & 0.076082 & $0.027^{*}$ \\
C2 & $0.24409(18)$ & $0.25668(17)$ & $0.28849(13)$ & $0.0130(2)$ \\
C3 & $0.28477(18)$ & $0.30711(17)$ & $0.41944(12)$ & $0.0134(3)$ \\
H3 & 0.354591 & 0.209469 & 0.492774 & $0.016^{*}$ \\
C4 & $0.22279(18)$ & $0.49457(17)$ & $0.43721(12)$ & $0.0123(2)$ \\
C5 & $0.25280(17)$ & $0.57338(17)$ & $0.56325(12)$ & $0.0125(2)$ \\
C6 & $0.19936(18)$ & $0.77347(18)$ & $0.56231(13)$ & $0.0145(3)$ \\
H6 & 0.143243 & 0.859198 & 0.479371 & $0.017^{*}$ \\
C7 & $0.22719(19)$ & $0.84865(18)$ & $0.68094(13)$ & $0.0161(3)$ \\
H7 & 0.189996 & 0.984671 & 0.680682 & $0.019^{*}$ \\
C8 & $0.31034(19)$ & $0.72021(19)$ & $0.79907(13)$ & $0.0155(3)$ \\
C9 & $0.33530(19)$ & $0.44896(18)$ & $0.68597(13)$ & $0.0150(3)$ \\
H9 & 0.371753 & 0.312707 & 0.687739 & $0.018^{*}$ \\
C10 & $0.36460(19)$ & $0.52178(19)$ & $0.80508(13)$ & $0.0165(3)$ \\
H10 & 0.420531 & 0.437336 & 0.888573 & $0.020^{*}$ \\
C11 & $0.07485(19)$ & $0.59398(18)$ & $0.20336(12)$ & $0.0147(3)$ \\
C12 & $0.14505(18)$ & $0.39537(18)$ & $0.18272(12)$ & $0.0144(3)$ \\
H12 & 0.122569 & 0.360313 & 0.095264 & $0.017^{*}$ \\
\hline & & & &
\end{tabular}

of ethyl (Z)-5-(4-fluorophenyl)-5-hydroxy-3-oxopent-4-enoate $(0.23 \mathrm{~g}, \quad 0.9 \mathrm{mmol})$ and 1,8-diazobicyclo[5.4.0]undecan-7ene (DBU, $0.16 \mathrm{~g}, 1.0 \mathrm{mmol}$ ) in benzene $(5 \mathrm{~mL})$ overnight, according to the method described by Cervello et al. [5],

This work is licensed under the Creative Commons Attribution 4.0 Public 
led to base-mediated cyclization to yield 6-(4-fluorophenyl)-4hydroxy-2H-pyran-2-one. Methylation of the product $(0.41 \mathrm{~g}$, $2.0 \mathrm{mmol})$ with dimethyl sulfate $(0.38 \mathrm{~g}, 3.0 \mathrm{mmol})$ in the presence of potassium carbonate $(0.8 \mathrm{~g}, 6.0 \mathrm{mmol})$ afforded the product 6-(4-fluorophenyl)-4-methoxy- $2 \mathrm{H}$ pyran-2-one. Crystals were obtained by hot recrystallization using methanol. Yield $=97 \%$, m.p. $202-206{ }^{\circ} \mathrm{C}$. ${ }^{1} \mathbf{H}$ NMR $\left(400 \mathrm{MHz}, \mathrm{CDCl}_{3}\right) \delta[\mathrm{ppm}]=7.80(\mathrm{ddd}, 2 \mathrm{H}, J=7.1,5.2,2.1 \mathrm{~Hz})$, $7.13(\mathrm{t}, 2 \mathrm{H}, J=8.7), 6.35(\mathrm{~d}, 1 \mathrm{H}, J=2.1 \mathrm{~Hz}), 5.53(\mathrm{~d}, 1 \mathrm{H}$, $J=2.1 \mathrm{~Hz}$ ), $3.85\left(\mathrm{~s}, 3 \mathrm{H}, \mathrm{OCH}_{3}\right) \cdot{ }^{13} \mathbf{C}$ NMR (400 MHz, $\mathrm{CDCl}_{3}$ ) $\delta[\mathrm{ppm}]=171.4,164.5(\mathrm{~d}, J=252.4 \mathrm{~Hz}), 164.1,159.4,128.0(\mathrm{~d}$, $J=8.7 \mathrm{~Hz}), 127.5(\mathrm{~d}, J=3.5 \mathrm{~Hz}), 116.2(\mathrm{~d}, J=22.1 \mathrm{~Hz}), 97.9(\mathrm{~d}$, $J=1.1 \mathrm{~Hz}), 88.5,56.2\left(\mathrm{OCH}_{3}\right) .{ }^{19} \mathbf{F}$ NMR $\left(400 \mathrm{MHz}, \mathrm{CDCl}_{3}\right) \delta$ $[\mathrm{ppm}]=-108.50(\mathrm{~m})$. HRMS-ESI $(+)$ calcd. for $\mathrm{C}_{12} \mathrm{H}_{9} \mathrm{FO}_{3} \mathrm{Na}$ $[\mathrm{M}+\mathrm{Na}]+243.0433$, found 243.0433. IR (neat) $\left(\mathrm{cm}^{-1}\right)=1727$, 1265, 1217, 1165, 1069, 1008, 839, 797.

\section{Experimental details}

The visual crystal structure information was performed using Mercury [4] system software. All $\mathrm{C}-\mathrm{H}_{\text {aromatic }} \mathrm{C}-\mathrm{H}_{\text {methyl }}$ and $\mathrm{C}-\mathrm{H}_{\text {methylene }}$ bond distances were restrained to $0.95 \AA, 0.98 \AA$ and $0.99 \AA$ with $U_{\text {iso }}\left(\mathrm{H}_{\text {aromatic }}\right.$ and $\left.\mathrm{H}_{\text {methylene }}\right)=1.2 U_{\text {eq }}$ and $U_{\text {iso }}\left(\mathrm{H}_{\text {methyl }}\right)=1.5 U_{\text {eq }}$ of parent atom, respectively.

\section{Comment}

Many biologically active compounds containing a 2-pyrone moiety are known [6]. These compounds and synthetic analogues are associated with a diverse range of biological activities such as antiviral [7], anti-malarial, and anti-tuberculosis activities [8], hence there is an ongoing interest in the synthesis of these compounds. Several studies have shown that the incorporation of fluorine in molecules are likely to enhance the biological activities [9], which stimulated our interest in the synthesis of fluorinated 2-pyrones [10].

The crystal structure of the title compound has one molecular unit consisting of 4-fluorophenyl and pyrone moieties. Compared to the non-fluorinated molecule, the presence of the fluorine atom decreased the dihedral angle between the 4-fluorophenyl and pyrone rings from $8.8^{\circ}$ to $7.2^{\circ}$ [11]. Furthermore, the methoxy group was found to be more co-planar with the pyrone ring given a $\mathrm{C} 1-\mathrm{O} 1-\mathrm{C} 2-$ C12 torsion angle of $-0.5^{\circ}$ compared to that observed in the non-fluorinated derivative [11]. Non-classical intermolecular C12-H12...03 (symmetry code: $-x, 1-y,-z$ ) and C10-H10 ‥F1 (symmetry code: $1-x, 1-y, 2-z$ ) hydrogen bonds form alternating eight-membered rings with two donor atoms and an acceptor. These hydrogen bonding patterns link neighbouring molecules to form a one-dimensional supramolecular structure.

Acknowledgements: This work was supported by the University of KwaZulu-Natal and the National Research Foundation of South Africa (NRF) (Grant No: 98345, 2018).

\section{References}

1. Bruker. APEXII. Bruker AXS Inc., Madison, WI, USA (2009)

2. Sheldrick, G. M.: A short history of SHELX. Acta Crystallogr. A64 (2008) 112-122.

3. Sheldrick, G. M.: Crystal structure refinement with SHELXL. Acta Crystallogr. C71 (2015) 3-8.

4. Macrae, C. F.; Bruno, I. J.; Chisholm, J. A.; Edgington, P. R.; McCabe, P.; Pidcock, E.; Rodriguez-Monge, L.; Taylor, R.; van de Streek, J.; Wood, P. A.: Mercury CSD 2.0 - new features for the visualization and investigation of crystal structures. J. Appl. Crystallogr. 41 (2008) 466-470.

5. Cervello, J.; Marquet, J.; Moreno-Mañas, M.: Copper and cobalt mediated regioselective alkylation of polyketide models: methyl 3,5-dioxohexanoate and triacetic acid lactone. Tetrahedron 46 (1990) 2035-2046.

6. McGlacken, G. P.; Fairlamb, I. J.: 2-Pyrone natural products and mimetics: isolation, characterisation and biological activity. Nat. Prod. Rep. 22 (2005) 369-385.

7. Defant, A.; Mancini, I.; Tomazzolli, R.; Balzarini, J.: Design, synthesis, and biological evaluation of novel $2 \mathrm{H}$-pyran-2-one derivatives as potential HIV-1 reverse transcriptase inhibitors. Arch. Pharm. 348 (2015) 23-33.

8. McCracken, S. T.; Kaiser, M.; Boshoff, H. I.; Boyd, P. D.; Copp, B. R.: Synthesis and antimalarial and antituberculosis activities of a series of natural and unnatural 4-methoxy-6styryl-pyran-2-ones, dihydro analogues and photo-dimers. Bioorg. Med. Chem. 20 (2012) 1482-1493.

9. Hagmann, W. K.: The many roles for fluorine in medicinal chemistry. J. Med. Chem. 51 (2008) 4359-4369.

10. Obi, G.; Van Heerden, F. R.: Synthesis of 5,6-dehydrokawain and some fluorinated analogues. Synth. Commun. 48 (2018) 1482-1486.

11. Obi, G.; Zamisa, S. J.; Van Heerden, F. R.: Crystal structure of 4-methoxy-6-phenyl-2H-pyran-2-one, $\mathrm{C}_{12} \mathrm{H}_{10} \mathrm{O}_{3}$. Z. Kristallogr. NCS 233 (2018) 343-344. 